\title{
RARE ELEMENTS (ZR, NB, LA, CE AND HF) IN TRAFFIC EMITTED FERRIMAGNETIC PARTICLES FROM ROAD DUSTS
}

\author{
Bourliva A. ${ }^{1}$, Papadopoulou L. ${ }^{1}$, Aidona E. ${ }^{2}$ and Pipera K. ${ }^{1}$ \\ ${ }^{I}$ Department of Mineralogy-Petrology-Economic Geology, School of Geology, Aristotle University \\ of Thessaloniki, 54124,Thessaloniki, Greece,annab@geo.auth.gr,lambrini@geo.auth.gr, \\ piperakir@gmail.gr \\ ${ }^{2}$ Department of Geophysics, School of Geology, Aristotle University of Thessaloniki, 54124 \\ Thessaloniki, Greece, aidona@geo.auth.gr
}

\begin{abstract}
In the present study, the presence and the elemental contents of some rare elements such as zirconium $(\mathrm{Zr})$, niobium $(\mathrm{Nb})$, lanthanum $(\mathrm{La})$, cerium $(\mathrm{Ce})$ and hafnium $(\mathrm{Hf})$ in different fractions (bulk samples, non-magnetic fraction-NMF and magnetic fraction$M F)$ of road dusts from the city of Thessaloniki, were investigated. The mean $\mathrm{Zr}, \mathrm{Nb}$, $\mathrm{La}, \mathrm{Ce}$ and $\mathrm{Nb}$ concentrations in the bulk road dust samples were 32.1, 5, 16.4, 40 and

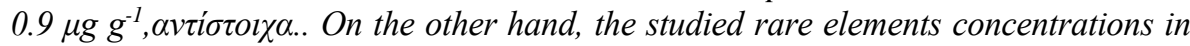
magnetic fractions (MFs) were enriched and the enrichment ratios, defined as the concentration ratio of metals in MFs and NMFs, ranged between $1.9(\mathrm{Ce})$ and $7.9(\mathrm{Nb})$. Pearson's correlation coefficients in the MFs indicated 3 groups of elements originating from common source: a) $\mathrm{Zr}-\mathrm{Hf}-\mathrm{Cr}-\mathrm{Cu}-\mathrm{Mo}-\mathrm{Sn}-\mathrm{Sb}$, b) $\mathrm{Nb}-\mathrm{Ni}-\mathrm{Cu}-\mathrm{Mo}-\mathrm{Sn}$ and c) $\mathrm{La}-\mathrm{Ce}$. The significant correlations of the $\mathrm{Zr}, \mathrm{Hf}$ and $\mathrm{Nb}$ with elements such as $\mathrm{Cu}, \mathrm{Sb}$, Sn and Mo which are characteristic of brake wear emissions indicated that the emission of these elements in the urban environment can also be attributed to vehicular traffic as they are highly associated with traffic emitted ferrimagnetic particles.

Keywords: road dust, rare metals, magnetic particles, traffic emissions, Thessaloniki.
\end{abstract}

\section{Пєрí $\eta \psi \eta$}

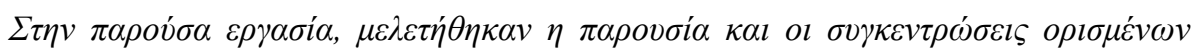

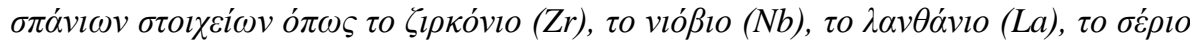

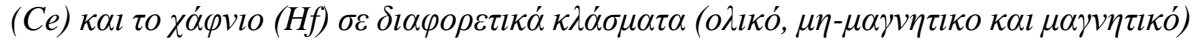

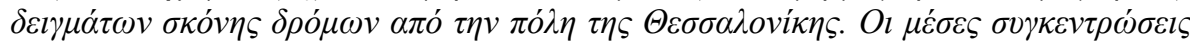

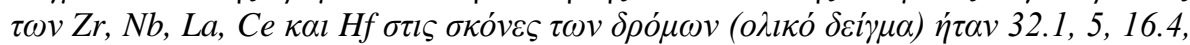

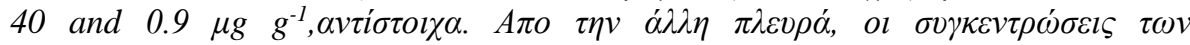

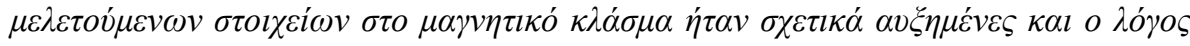

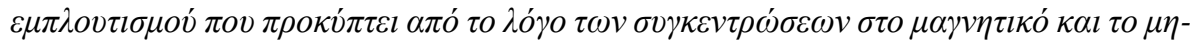

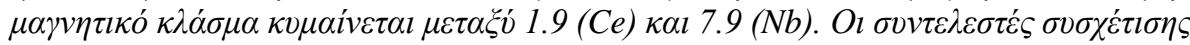

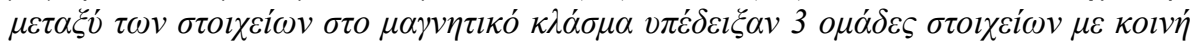

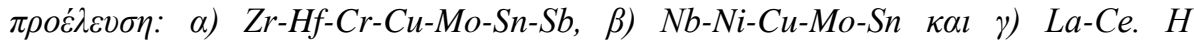

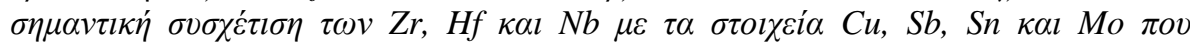

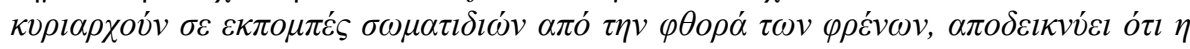

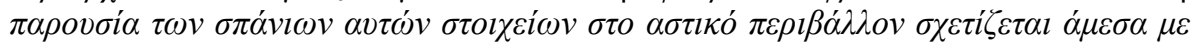




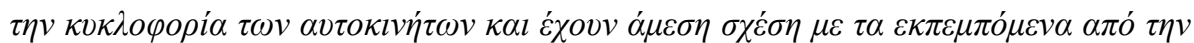

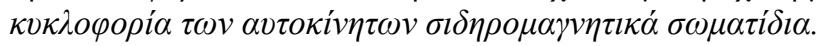

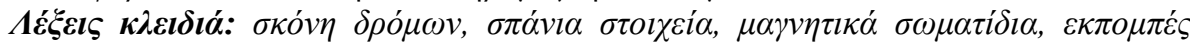

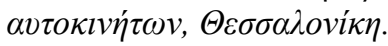

\section{Introduction}

In recent years the anthropogenic magnetic particles contained in suspended dusts have been studied with an increased frequency (Sagnotti et al., 2006; Bućko et al., 2010). In urban areas, in the absence of heavy industry, circulation of motor vehicles is considered among the most important sources of magnetic particles emission into the environment (Shilton et al., 2005; Bućko et al., 2010; Yang et al., 2010). The past investigations concentrated mostly on the correlation of traffic emitted ferrimagnetic particles with toxic heavy metals (Goddu et al., 2004). However, a number of other rare elements i.e. $\mathrm{Zr}, \mathrm{Nb}, \mathrm{La}, \mathrm{Ce}$ and $\mathrm{Hf}$ are also released into the environment and are identified as traffic emitted elements.

Rare earth elements such as La and Ce have become extremely interesting in the last decades, owing to increasing use of these elements in car catalysts. The vehicles catalytic converters contain also a number of stabilizers, commonly oxides of rare earth elements and alkaline earth elements such as $\mathrm{Ce}, \mathrm{La}$ and $\mathrm{Zr}$, which stabilize the catalyst support (a $\gamma$-alumina based honeycomb) and enhance the oxidation of pollutants (Lyubomirova et al., 2011). On the other hand zirconium (Zr) and hafnium (Hf) are less studied although their concentrations in road dust are also correlated with traffic emissions. On the contrary, appears to be very little information on $\mathrm{Nb}$ in the urban environment and as concluded it is unlikely that motor vehicles are significant sources of $\mathrm{Nb}$ in the urban environment (Kennedy, 2003).

Since vehicular emission of rare elements has received little attention so far and the obtained results are mainly based on whole dust samples and not on individual separated magnetic phases, the present study attempts to offer insight into their concentration and enrichment in magnetic extracts from urban road dust samples.

\section{Materials and Methods}

\subsection{Sample Collection and Magnetic Separation}

Road dust samples (each weighting almost $100 \mathrm{~g}$ ) were collected from selected roads in Thessaloniki's city core (5 sampling locations) (Fig. 1). Road dusts were collected twice within a gap of 5 months before and almost at the end of the dry season (April and September) in the year 2014. The dust samples were mainly collected by gently sweeping at all sites a comparable area of one square meter $\left(1 \mathrm{~m}^{2}\right)$ from pavement edges using clean plastic dustpans and brushes for each sampling site. Care was taken to reduce the disturbance of fine particles. Samples (bulk sample) were dried in an oven at $35^{\circ} \mathrm{C}$ for 3 days and mechanically sieved and the $<250-\mu \mathrm{m}$ size fraction was used for subsequent analyses. The magnetic extracts were obtained by using a hand magnet sealed with a propylene bag. The extraction procedure was run continuously until no magnetic particles were attached to the magnet. The extracted magnetic fractions (MFs) and the residue (hereafter called non-magnetic fractions, NMFs) were collected and weighed.

\subsection{Geochemical Analyses and Magnetic Measurements}

The concentration of a total of 45 elements including the studied rare metals ( $\mathrm{Zr}, \mathrm{Nb}, \mathrm{La}, \mathrm{Ce}$, and $\mathrm{Hf}$ ) were determined in different road dust fractions (bulk sample, magnetic fraction-MF and nonmagnetic fraction-NMF) using inductively coupled plasma mass spectrometry (ICP-MS) after a multi acid digestion procedure at the accredited Acme Analytical Laboratories, Canada. Specifically, about $0.25 \mathrm{~g}$ of the prepared dust sample was heated in a concentrated $\mathrm{HF}-\mathrm{HNO}_{3}-\mathrm{HClO}_{4}$ mixture to fuming and taken to dryness. The residue was dissolved in $\mathrm{HCl}$. Quality assurance and quality 
control (QA/QC) included reagent blanks, analytical duplicates and analyses of certified reference materials (multi-element soil standard OREAS25A-4A and OREAS45E). Results of the method blanks were always below detection limits. The recovery rates were estimated within $\pm 10 \%$ of the certified value, and analytical precision was better than $\pm 5 \%$. Mass specific magnetic susceptibility $(\chi)$ of dust samples was measured at low $(0.46 \mathrm{kHz})$ and high $(4.6 \mathrm{kHz})$ frequency using a Bartington MS2 laboratory magnetic susceptibility meter (Bartington Ltd., UK), equipped with a dual frequency MS2B sensor. Magnetic susceptibility value provides an indication of the concentration within the sample of strongly ferrimagnetic minerals, such as magnetite.

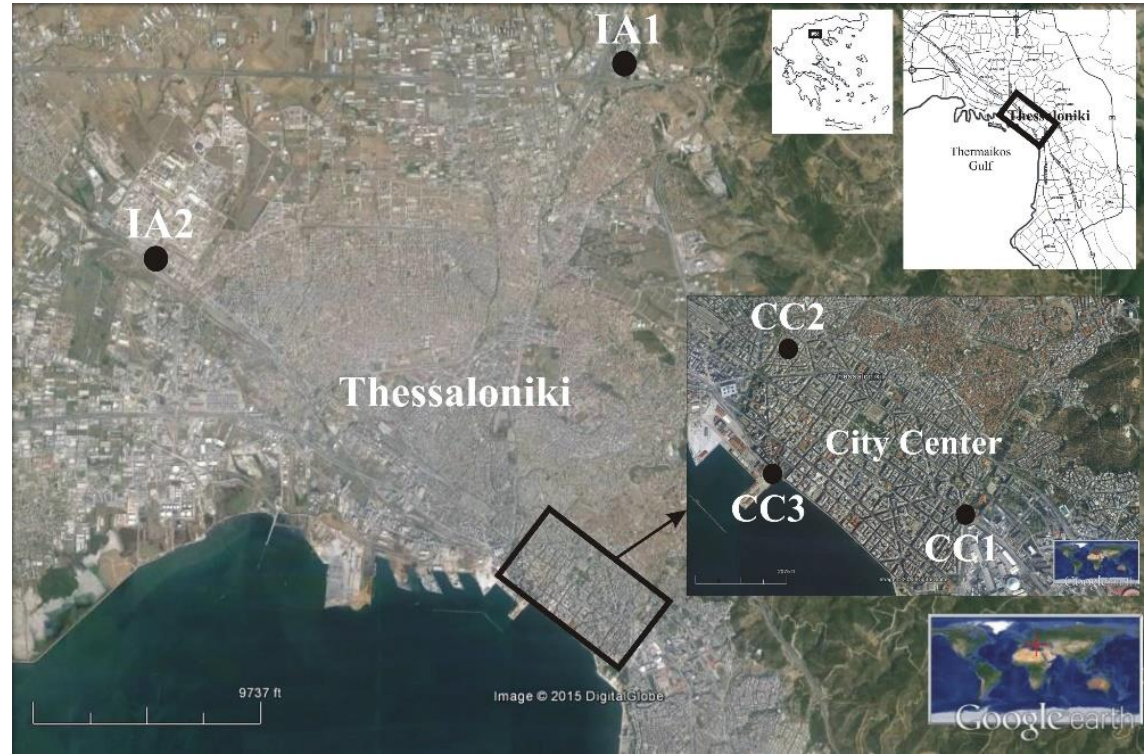

Figure 1 - Map of study area and sampling sites of road dust samples. CC: city center, IA: industrial area.

\section{Results and Discussion}

\subsection{Magnetic Properties and Elemental Contents of Road Dust Samples}

Road dusts exhibited values of mass specific magnetic susceptibility $\left(\chi_{\mathrm{lf}}\right)$ ranging between $122.5 \times 10^{-}$ ${ }^{8}$ and $638.7 \times 10^{-8} \mathrm{~m}^{3} \mathrm{~kg}^{-1}$, indicating the presence of a considerable amount of ferrimagnetic iron oxides (Bourliva et al., 2015). The contents of MFs in road dusts varied between 2.2 and $14.7 \mathrm{wt} \%$.

Road dusts are dominated by $\mathrm{Ca}(12.08-27.72 \%)$, while lower abundances of $\mathrm{Al}$ and $\mathrm{Fe}$ occurred with their concentrations ranging between 1.04 and $3.92 \%$ and 0.61 and $3.91 \%$, respectively. $\mathrm{Mg}$, $\mathrm{Na}$, K and Ti presented lower quantities with mean values below 1\% (Bourliva et al., 2015). In order to have a clear view and to differentiate between natural and anthropogenic loads, the elemental concentrations of the different road dust fractions (bulk samples, NMFs and MFs) were normalized to the bulk continental crust values (Taylor and McLennan, 1995) and the results are presented in Figure 2.

As shown, large-ion lithophile elements (LILE) such as potassium, rubidium, strontium, and barium along with some light rare earth elements (LREE) such as lanthanum (La) and cerium (Ce) which are considered as crustal components, were depleted in the bulk road dusts. Iron as it was expected, was depleted in NMFs and highly enriched in MFs, while $\mathrm{Ca}, \mathrm{Al}, \mathrm{Na}$, and $\mathrm{K}$ were depleted in the MFs, indicating that these elements are associated with the non-magnetic dust particles mainly of crustal origin (Bourliva et al., 2015). The elements of considerable anthropogenic impacts in road dusts (both bulk samples and MFs) are $\mathrm{Cu}, \mathrm{Zn}, \mathrm{As}, \mathrm{Mo}, \mathrm{Sn}, \mathrm{Sb}, \mathrm{Pb}$ and Bi (Fig. 2). On the other 
hand, elements such as $\mathrm{Cr}$ and $\mathrm{W}$ which reflect anthropogenic input were not presented highly enriched in the bulk road dusts, while their normalized elemental concentrations were significantly higher in the MFs exhibiting an anthropogenic origin related to the ferrimagnetic dust particles.

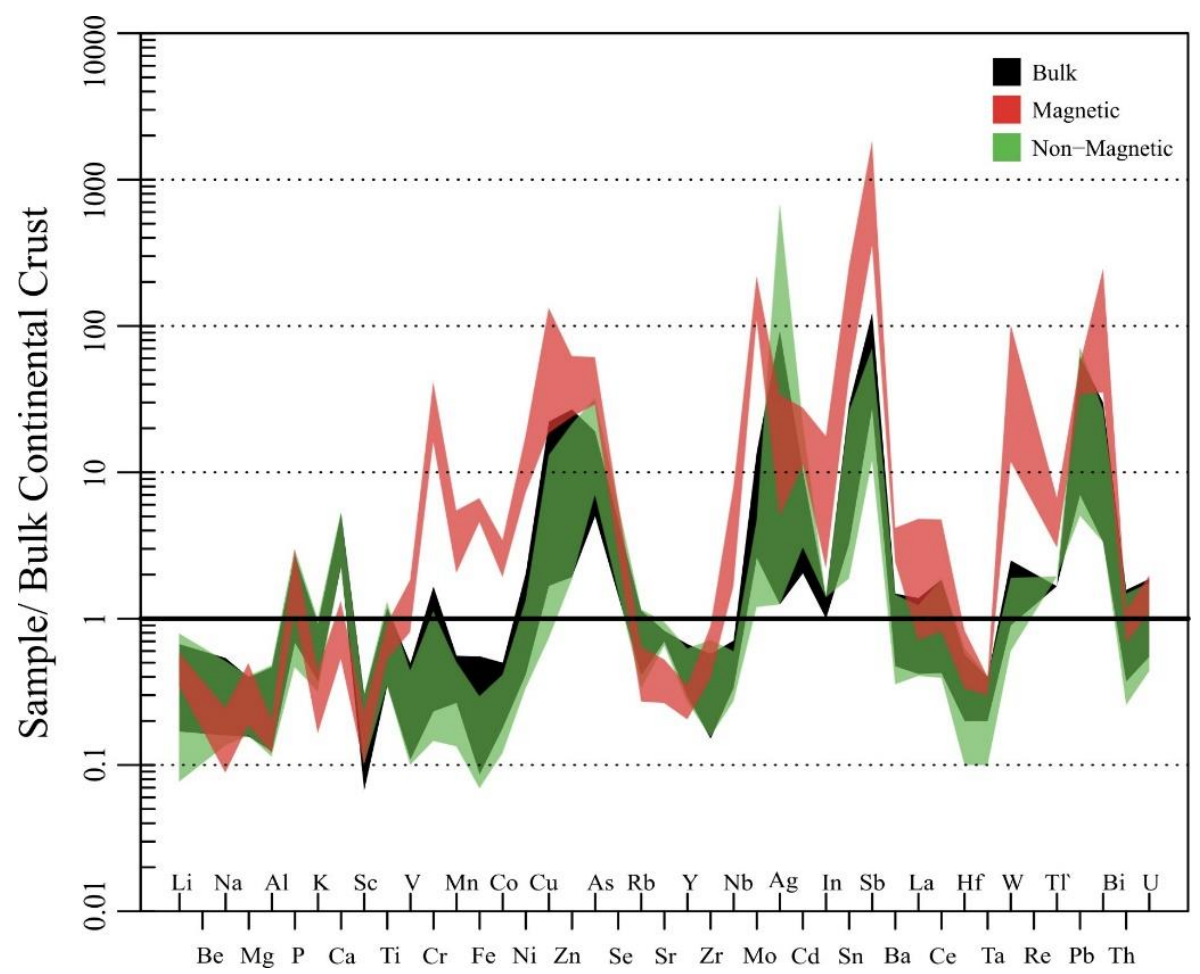

Figure 2 - Elemental concentrations of the different road dust fractions (bulk sample, nonmagnetic fraction and magnetic fraction) normalized to bulk continental crust values. Normalization values after Taylor and McLennan (1995).

Elevated concentrations of metals such as $\mathrm{Cu}$ and $\mathrm{Zn}$ in road dusts are attributed to tire and break wear (Thorpe and Harrison 2008). Furthermore, $\mathrm{Cr}, \mathrm{Cu}, \mathrm{Ni}, \mathrm{Pb}$ and $\mathrm{Zn}$ are abundant metals in brake lining materials (Westerlund and Johansson, 2002), while brake wear emissions have been cited as a potentially important source of $\mathrm{Sb}$ and $\mathrm{Sn}$ emissions to the environment (Thorpe and Harrison 2008). Kennedy and Gadd (2003) presented evidence to suggest that brake dust is enriched in $\mathrm{Cr}$, $\mathrm{Cu}, \mathrm{Fe}$, and $\mathrm{Sn}$. On the other hand, molybdenum (Mo) is used primarily in steel alloys, many of which are used in automotive industry, while tires and brake pads contained low concentrations of Mo (Kennedy and Gadd, 2003). As far as Pb is concerned, after the prohibition of its use as a fuel additive for gasoline, brake wear emissions may represent a significant source of airborne $\mathrm{Pb}$ (Westerlund and Johansson, 2002).

\subsection{Rare Elements Content in Road Dust Samples}

The range and the mean concentrations of the rare elements $\mathrm{Zr}, \mathrm{Nb}, \mathrm{La}, \mathrm{Ce}$ and $\mathrm{Hf}$ in bulk road dusts and the non-magnetic and magnetic fractions are presented in Table 1. As shown in Table 1, bulk road dusts exhibited concentration ranges from 15.1 to $57.4 \mu \mathrm{g} / \mathrm{g}$ for $\mathrm{Zr}$, from 3.7 to $7.8 \mu \mathrm{g} / \mathrm{g}$ for Nb , from 6.7 to $22.1 \mu \mathrm{g} / \mathrm{g}$ for La, from 14 to $61 \mu \mathrm{g} / \mathrm{g}$ for Ce and from 0.60 to $1.70 \mu \mathrm{g} / \mathrm{g}$ for Hf respectively. The mean concentrations of these rare elements decreased in the order $\mathrm{Ce}>\mathrm{Zr}>\mathrm{La}>\mathrm{Nb}>\mathrm{Hf}$. 
Table 1 - Minimum, Maximum, Mean and Median Concentrations of Rare Elements in different fractions of road dust samples from the city of Thessaloniki.

\begin{tabular}{|l|c|c|c|c|c|c|c|c|c|c|c|c|}
\hline \multirow{2}{*}{ Elements } & \multicolumn{4}{|c|}{ Bulk } & \multicolumn{3}{c|}{ Non-Magnetic Fraction } & \multicolumn{4}{c|}{ Magnetic Fraction } \\
\cline { 2 - 14 } & Min & Max & Mean & Median & Min & Max & Mean & Median & Min & Max & Mean & Median \\
\hline $\mathbf{Z r}$ & 15.1 & 57.4 & 32.1 & 25.0 & 15.6 & 71.6 & 32.8 & 31.8 & 39.0 & 88.8 & 70.6 & 72.6 \\
\hline $\mathbf{N b}$ & 3.7 & 7.8 & 5.0 & 4.2 & 3.0 & 6.6 & 4.3 & 4.1 & 18.4 & 88.2 & 31.2 & 21.8 \\
\hline $\mathbf{L a}$ & 6.7 & 22.1 & 16.4 & 16.3 & 6.5 & 19.8 & 14.2 & 14.8 & 11.4 & 76.8 & 30.2 & 23.9 \\
\hline $\mathbf{C e}$ & 14 & 61 & 40 & 32 & 13 & 62 & 41.4 & 43 & 27 & 157 & 71.2 & 64.5 \\
\hline Hf & 0.60 & 1.70 & 0.90 & 0.70 & 0.30 & 1.90 & 0.95 & 0.95 & 1.00 & 2.50 & 1.82 & 1.85 \\
\hline
\end{tabular}

According to the elemental concentrations normalized to bulk continental crust, zirconium ( $\mathrm{Zr}$ ), niobium $(\mathrm{Nb})$, lanthanum (La), cerium $(\mathrm{Ce})$ and hafnium (Hf) are depleted in the bulk road dusts (Fig. 2). Furthermore, cerium (Ce) appeared more enriched compared to lanthanum, which is not normal for crustal rocks and enforced the fact that there were low crustal influences in road dust samples. On the contrary, in the MFs and taking into account the normalized values niobium $(\mathrm{Nb})$ appeared enriched, while $\mathrm{La}$ and $\mathrm{Ce}$ are enriched in most of the cases in the MFs. On the other hand, $\mathrm{Zr}$ and Hf though presenting higher concentrations in the MFs are considered still depleted in the MFs (Fig. 2).

In order to evaluate the correlation of the studied rare elements with the NMFs and MFs, the enrichment ratios of the studied rare elements, which are defined as the concentration ratio of elements in magnetic fraction to non-magnetic fraction, were determined and are presented in Figure 3.

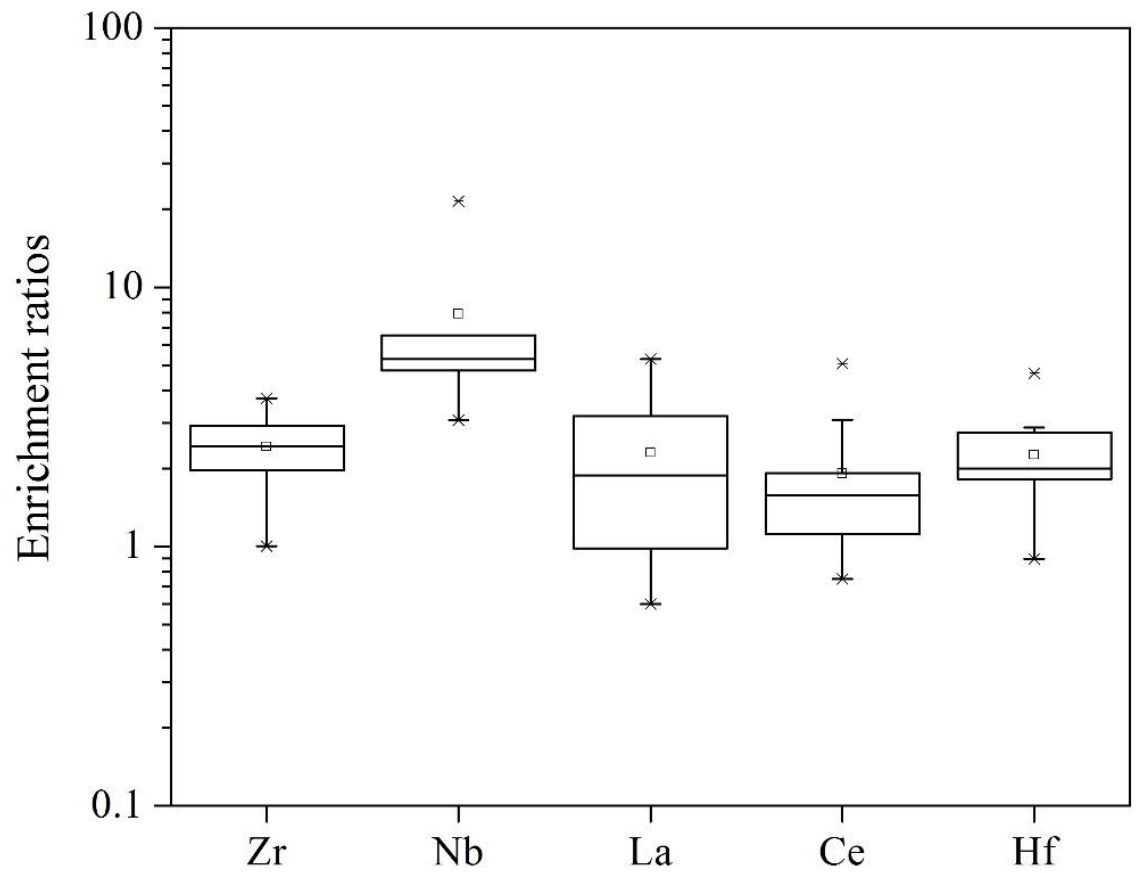

Figure 3 - Enrichment ratios of rare elements of road dusts.

As shown, the mean enrichment ratios ranged between $1.9(\mathrm{Ce})$ and $7.9(\mathrm{Nb})$ decreasing in the order $\mathrm{Nb}>\mathrm{Zr}>\mathrm{La}>\mathrm{Hf}>\mathrm{Ce}$. Though the enrichment ratios presented low values for some of the studied rare elements, these elements could be considered related to the ferrimagnetic dust particles. Specifically, niobium which presented significantly high enrichment ratios exhibiting in some cases concentrations more than 15 times higher in the MF, its correlation with the ferrimagnetic particles could be considered certain. Furthermore, the positive anomaly of $\mathrm{Nb}$ compared to the negative 
anomaly of tantalum (Ta) in the MFs, which are transition metals almost always paired together in nature, enforced the anthropogenic origin of $\mathrm{Nb}$ in road dust samples (Fig. 2).

\subsection{Traffic Related Rare Elements in Road Dusts Magnetic Fractions}

In order to identify the possible sources of $\mathrm{Zr}, \mathrm{Nb}, \mathrm{La}, \mathrm{Ce}$ and $\mathrm{Hf}$ in the ferrimagnetic dust particles, inter-element relations in the magnetic fraction were determined and the correlation diagrams of the pairs which presented significant correlations $(p<0.05)$ are illustrated in Figure 4. As shown, zirconium and hafnium presented good correlation with the same elements i.e. $\mathrm{Cr}, \mathrm{Cu}, \mathrm{Mo}, \mathrm{Sn}$ and $\mathrm{Sb}$ and along with their strong positive correlation $\left(\mathrm{r}_{\mathrm{Zr}-\mathrm{Hf}}=0.976\right)$ indicated a group of elements with probable common source. Additionally, niobium $(\mathrm{Nb})$ presented good correlations with $\mathrm{Ni}, \mathrm{Cu}, \mathrm{Mo}$ and Sn. Generally, the good correlation of the studied rare metals with metals which were highly enriched in the road dusts MFs also suggested an anthropogenic origin of these elements in the ferrimagnetic particles.

Specifically, the strong correlations between $\mathrm{Zr}, \mathrm{Hf}$, and $\mathrm{Nb}$ with elements such as $\mathrm{Cu}, \mathrm{Sb}, \mathrm{Cr}, \mathrm{Sn}$, and Mo which are attributed to brake wear emissions, enforce the fact that $\mathrm{Zr}$, $\mathrm{Hf}$ and $\mathrm{Nb}$ in the road dusts magnetic fraction are traffic related, originating from brake wear emissions. $\mathrm{Zr}\left(\mathrm{ZrSO}_{4}\right.$ as abrasive) and $\mathrm{Sb}$ (i.e. $\mathrm{Sb}_{2} \mathrm{~S}_{3}$ as solid lubricant) are used in friction materials for an automotive brake system (Jang and Kim, 2000). Additionally, metals such as Ti, Cr, Zr, Al and $\mathrm{Hf}$ can be used as coating materials in automotive brake pads. On the other hand, niobium is used as a microalloying element in high strength steels for automotive applications (Mohrbacker, 2006) and along with chromium, nickel, copper, titanium and molybdenum, can be used in grey iron alloys for vehicle brake disc (http://www.niobelcon.com).

As far as the rare earth elements lanthanum (La) and cerium (Ce) are concerned, they exhibited a high positive correlation $\left(\mathrm{r}_{\mathrm{La}-\mathrm{Ce}}=0.958\right)$ indicating their chemical association and their derivation from a common source which probable is the catalytic converters. La and $\mathrm{Ce}$ are important components of the catalysts wash coat as they are added in order to improve or stabilize the catalytic activity of platinum group elements (PGEs). Ce is employed as a promoter in catalytic converters and is also a fuel additive (Jarvis et al., 2001; Rauch et al., 2002; Kan and Tanner, 2005; Lough et al., 2005).

\section{Conclusions}

In this present study, the presence of rare metals such as $\mathrm{Zr}, \mathrm{Nb}, \mathrm{La}, \mathrm{Ce}$ and $\mathrm{Hf}$ in road dusts from the city of Thessaloniki and its relation to traffic emitted iron-rich magnetic particles were investigated. Road dusts (bulk samples) exhibited significantly high contents in $\mathrm{Cu}, \mathrm{Zn}, \mathrm{As}, \mathrm{Mo}, \mathrm{Sn}$, $\mathrm{Sb}, \mathrm{Pb}$ with their concentrations being significantly higher than the background levels, reflecting anthropogenic influences in the road dusts. The mean concentrations of the studied rare elements decreased in the order $\mathrm{Ce}>\mathrm{Zr}>\mathrm{La}>\mathrm{Nb}>\mathrm{Hf}$, while according to the normalized values were depleted in the bulk road dusts. The enrichment ratios of the $\mathrm{Zr}, \mathrm{Nb}, \mathrm{La}, \mathrm{Ce}$ and $\mathrm{Hf}$ in the MFs indicated their preferred gather in the magnetic fractions and enforced the fact that are highly associated with the ferrimagnetic particles. Finally, the significant correlations among $\mathrm{Zr}$, Hf and $\mathrm{Nb}$ with elements associated with brake wear emissions such as $\mathrm{Cu}, \mathrm{Sb}, \mathrm{Sn}$ and $\mathrm{Mo}$, suggested their anthopogenic origin related to vehicular traffic. 

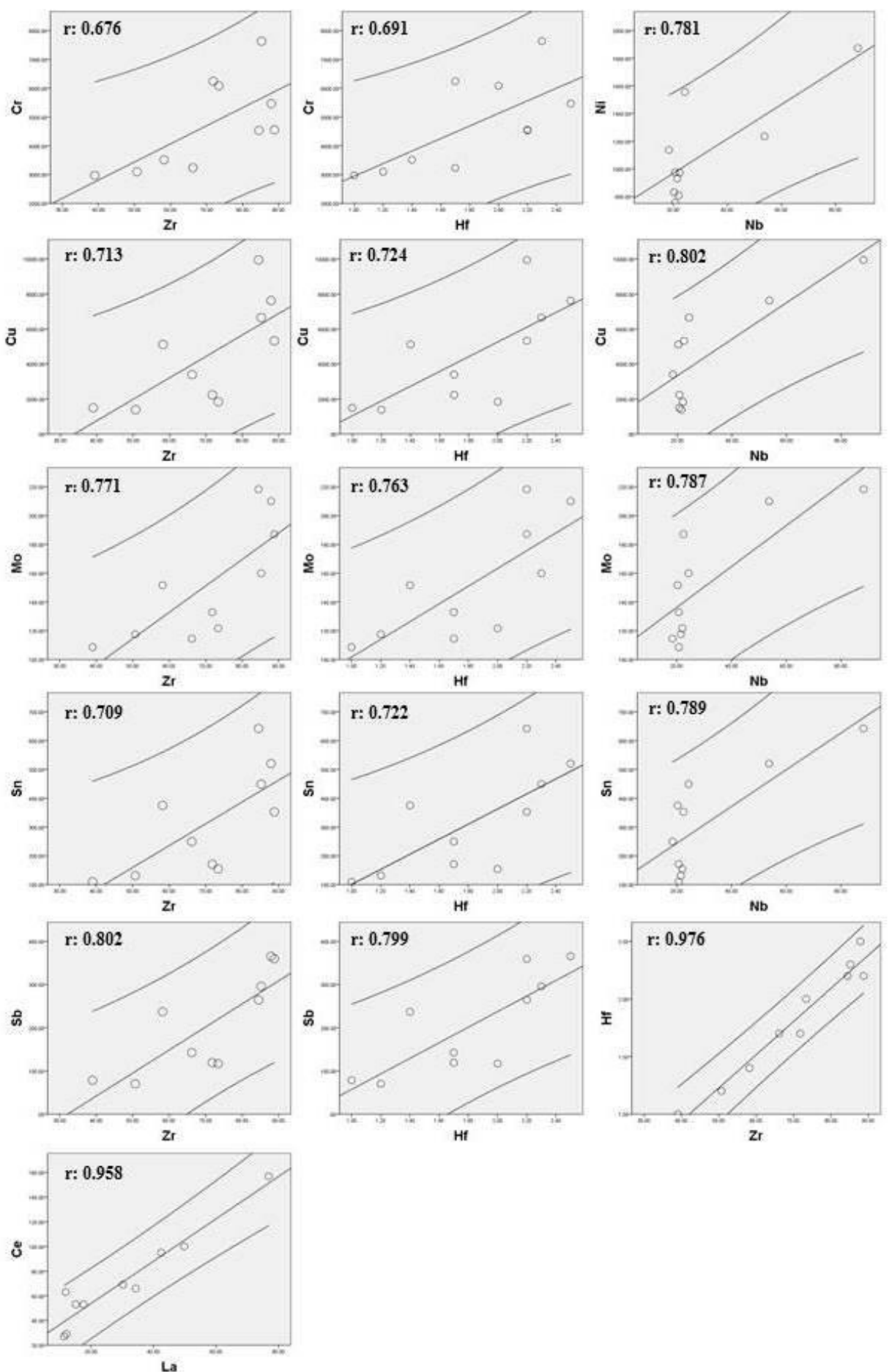

Figure 4 - Inter-element relations in the magnetic fraction of road dusts. The $\mathbf{r}$ value is the Pearson's correlation coefficient. 


\section{Acknowledgments}

The first author acknowledges financial support from IKY Fellowships of Excellence for Postgraduate Studies in Greece-Siemens Program.

\section{References}

Bourliva, A., Papadopoulou, L. and Aidona, E., 2015. Heavy metal content and health risk associated with magnetic particles in urban road dusts from Thessaloniki city center, Greece: Preliminary results, Proceedings of the $14^{\text {th }}$ International Conference on Environmental Science and Technology, e-Proceedings, CEST2015_00655.

Bućko, M.S., Magiera, T., Pesonen, L.J. and Janus, B., 2010. Magnetic geochemical, and microstructural characteristics of road dust on roadsides with different traffic volumes-case study from Finland, Water Air Soil Pollut., 209, 295-306.

Goddu, S.R., Appel, E., Jordanova, D. and Wehland, F., 2004. Magnetic properties of road dust from Visakhapatnam (India): relationship to industrial pollution and road traffic, Phys. Chem. Earth, 29, 985-995.

Jang, H. and Kim, S.J., 2000. The effects of antimony trisulfide $\left(\mathrm{Sb}_{2} \mathrm{~S} 3\right)$ and zirconium silicate $\left(\mathrm{ZrSiO}_{4}\right)$ in the automotive brake friction material on friction characteristics, Wear, 239, 229-236.

Jarvis, K., Parry, S. and Piper, J., 2001. Temporal and spatial studies of autocatalyst-derived platinum, rhodium, and palladium and selected vehicle-derived trace element in the environment, Environ. Sci. Technol., 35, 1031-1036.

Kan, S.F. and Tanner, P.A., 2005. Platinum concentrations in ambient aerosol at a coastal site in South China, Atmos. Environ., 39, 2625-2630.

Kennedy, P. and Gadd, J., 2003. Preliminary examination of trace elements in tyres, brake pads, and road bitumen in New Zealand, Report, Ministry of Transport, New Zealand.

Kennedy, P., 2003. Metals in particulate material on road surfaces, Report, Ministry of Transport, New Zealand.

Lough, G.C., Schauer, J.J., Park, J.S., Shafer, M.M., Deminter, J.T. and Weinstein, J.P., 2005. Emissions of metals associated with motor vehicle roadways, Environ. Sci. Technol., 39, 826-836.

Lyuborinova, V., Djingova, R. and van Elteren, J. T., 2011. Fractionation of traffic-emitted Ce, La and $\mathrm{Zr}$ in road dusts, J. Environ. Monit., 13, 1823-1830.

Mohrbacker, H., 2006. Niobium microalloyed automotive sheet steel-a cost effective solution to the challenges of modern body engineering. Proceedings of the International Symposium on Niobium Microalloyed Sheet Steel for Automotive Application, The Minerals, Metals \& Materials Society.

Rauch, S., Morrison, G.M. and Moldovan, M., 2002. Scanning laser ablation ICP-MS tracking of platinum group elements in urban particles, Sci. Total Environ., 286, 243-251.

Sagnotti, L., Macrì, P., Egli, R. and Mondino, M., 2006. Magnetic properties of atmospheric particulate matter from automatic air sampler stations in Latium (Italy): toward a definition of magnetic fingerprints for natural and anthropogenic PM10 sources, Geophys. Res., 111, B12S22, doi: 10.1029/2006JB004508.

Shilton, V.F., Booth, C.A., Smith, J.P., Giess, P., Mitchell, D.J. and Williams, C.D., 2005. Magnetic properties of urban street dust and their relationship with organic matter content in the West Midlands, UK, Atmos. Environ., 39, 3651-3659.

Taylor, S.R. and McLennan, S.M., 1995. The geochemical evolution of the continental crust, Reviews Geophys., 33, 241-265.

Thorpe, A. and Harrison, R.M., 2008. Sources and properties of non-exhaust particulate matter from road traffic: A review, Sci. Tot. Environ., 400, 270-282.

Westerlund, K.G. and Johansson, C., 2002. Emission of metals and particulate matter due to wear of brake linings in Stockholm, Air Pollut., 10, 793-802.

Yang, T., Liu, Q., Li, H., Zeng, Q. and Chan, L., 2010. Anthropogenic magnetic particles and heavy metals in the road dust: magnetic identification and its implications, Atmos. Environ., 44, 1175-1185.

http://www.niobelcon.com 